\title{
Comparison of Expansion Properties of Hot Water Valve from Three Different Materials
}

\author{
Oguzhan CANKAYA \\ Bursa Uludag University, Turkey, oguzhanc@uludag.edu.tr
}

\begin{abstract}
Polyamide stoiren acrylonitrile (SAN), polyamide 6.6 (PA66) and polymethyl methacrylate (PMMA) are three different materials considered as a possible alternative instead of hot water valve, produces by the company through conventional method by plastic injection machine. The goal of this paper is to propose the most suitable alternative among the three ones, using the examination of the thermal expansion coefficient and study the characteristic implication of different air pressure and temperatures simultaneously. The study was conducted with the specific designed experimental assembly and strain gauge software. The experimental results advise PA66 material as most suitable alternative of brass hot water valve.
\end{abstract}

Keywords

$\mathrm{CuZn} 40 \mathrm{~Pb}_{2}$, polyamide 6.6, stoiren acrylonitrile (SAN), polymethyl methacrylate (PMMA), strain gauge, expansion

\section{Introduction}

Increasing competition in the industry every day forces manufacturers finding new solutions for optimal costs' levels. Today, composite materials that are easy to manufacture, fast and cheap, but can withstand all working setbacks, have become preferred instead of production materials with high raw material costs. PA66, SAN and PMMA materials were selected, which are materials that can be produced more economically and quickly and can withstand the operating temperatures of the hot water valve, when considering the operating temperature of the hot water valve produced from the patented brass $\left(\mathrm{CuZn} 40 \mathrm{~Pb}_{2}\right)$ material of the company. Values obtained using strain gauge are compared using graphs.

The valve, which is made of brass material in the study, is produced by the company by casting method. In order to become the final product after production, processes are also required. Both the periods in the production method and the need for additional operations after production create October costs on the product. Given all these costs, it has made it mandatory to use a material that is cheaper, easier and has faster production in place of brass material.

In all areas, research on polymer-based composites has also increased with the increase in the need for lightweight but high-performance materials thanks to industries that are developing with high acceleration, such as the automotive, aerospace and defence industries [1]. The biggest reason for choosing composite materials is that they have low weight, high strength, chemical and corrosion resistance, high thermal performance properties [2].

Composite materials expected of a property of two or more elements created by bringing new and superior for the purpose [3]. Formed by making changes in the ratios of the components of the composite material can become superior. Composites are divided into fiber-reinforced, grain-reinforced and stratified composites. Stratified composites are formed by combining two or more layers [4]. In an elastic body subjected to thermal effect, various stress areas are formed according to the state of the boundary conditions and the temperature change function. Elasticity equations related to this topic have been deduced [5].

Expansion along with the increase in temperature, expansion occurs in all dimensions in solids. An expansion that occurs at length, widht and height is called a linear expansion. As a result, it is seen as the elongation of different materials at the same temperatures decidedly. Therefore, the amount of expansion formed in solids depends on the expansion coefficient of the materials. The amount of expansion is equals to $\Delta \mathrm{L}=\mathrm{L}_{0} \cdot \lambda$. Here, the amount of expansion in the size of the solid is called $\pm \mathrm{L}$, the 
initial dimension of the solid is called $L_{0}$, the temperature change is called $\pm T$, and the coefficient $\lambda$ is called the coefficient of thermal expansion or the coefficient of expansion in size. The expansion coefficient is a characteristic property for substances. Just as solids expand, plasters and gases expand. Expansion in solids and liquids is a distinctive feature, while expansion in gases is not a distinctive feature. Since the expansion of materials is also in the micrometer order, the methods to measure the expansion must be very precise. For this reason, strain gauge method, capacity method, interference methods were used in the measurement of the expansion coefficient [6].

For accurate detection of the expansion amounts in the strain gauge valves that were designed for use in this study, they were glued to make a with $45^{\circ}$ angle so that they could measure both coordinate systems. Calibration operations were performed and the instantaneous pressure and temperature obtained from the valves were recorded automatically. In the assembly designed for the simultaneous application of all conditions of three different valves designed for the experiment, apparatus were used to apply the given pressure to the valves at the same time.

\section{Materials and Method}

In the experiments, a special design experimental assembly was made so that the valves produced for comparison could be applied to air with different temperature and pressure values under the same conditions. In the experiment, three different materials were used as an alternative to the valve produced from brass CuZn40 $\mathrm{Pb}_{2}$. These materials used in the study are stoiren acrylonitrile (SAN), polyamide 6.6 (PA66) and polymethyl methacrylate (PMMA). The reason these materials are chosen is because they are easy and affordable as raw materials in the industry. The patent of the valve belongs to the company and its production is currently ongoing [7].

Figure 1 shows the hot water valve in three perspectives, produced from three different materials and used in the experiment, in which the company has a patent [7].

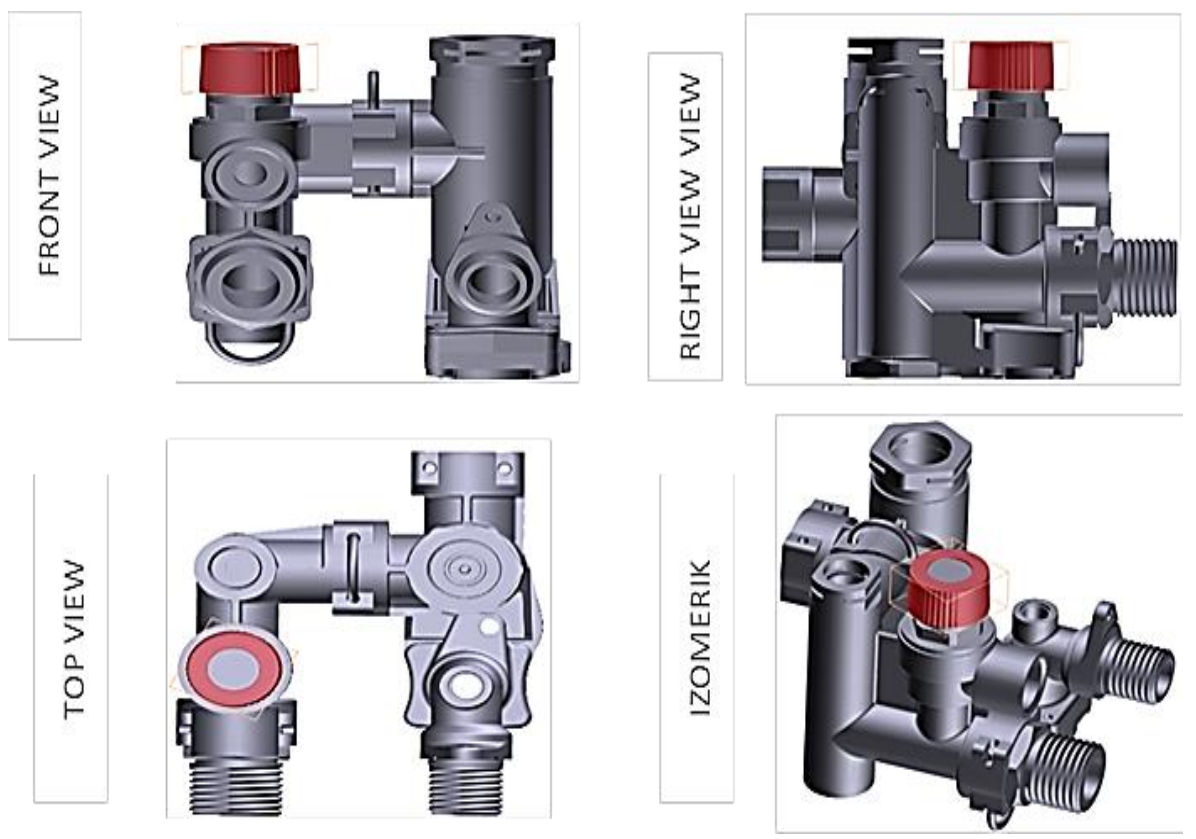

Fig. 1. Views of the valve from different angles

The mechanical properties of the brass $\mathrm{CuZn} 40 \mathrm{~Pb}_{2}$ valve, Fig. 2 (a), produced by the company by casting method are much higher than that required for the hot water valve used in the combi boiler.

In order to meet the combi boiler cost safe plan, the company need to determine the material with lower mechanical properties, less cost, shorter production time, and doesn't need additional after production processing, but meets the expected mechanical properties where necessary. All these requirements enforces three polymer materials easily available in the market and at much more affordable prices to be determined as suitable. 


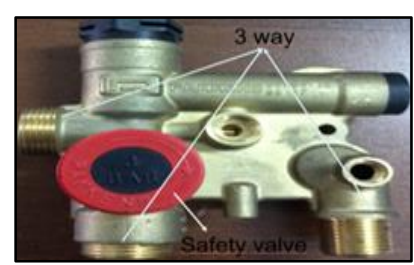

(a)

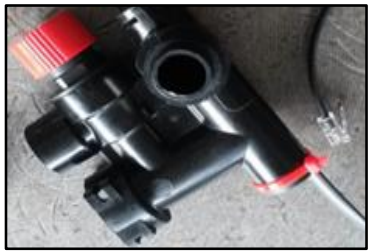

(b)

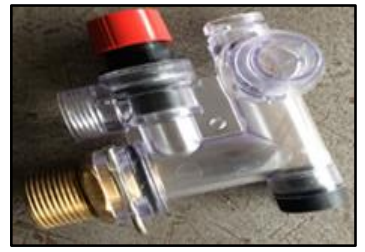

(c)

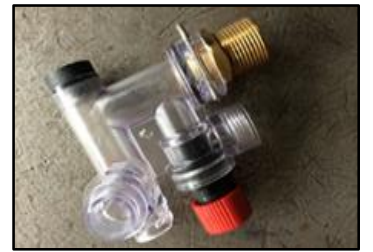

(d)

Fig. 2. Materials used: (a) brass CuZn40Pb; (b) PP66; (c) SAN; (d) PMMA

Polyamide 6.6, first found by Schlack in 1938, became widespread with its use in World War II. Polyamide 6.6 have high tensile strength, high resistance to abrasion and chemical [8]. Discoloration and reduction occur when exposed to heat for a long time. It ignites easily. Extensive research has been conducted to determine the advantages of polyamide 6.6 [9]. This material has the property of heat resistant, and hardness. In addition to its superior properties, it is widely used in the automotive industry as it can withstand solvent and hot water.

Styrene-acrylonitrile copolymers, found in 1937, are hard and brittle materials that are resistant to impact and chemicals. It is an amorphous and transparent thermoplastic polymer. Depending on its usage, the amount of acrylonitrile varies between 15-35\%. Excess acrylonitrile increases the hardness of the product, its resistance to heat and chemicals, and increases its mechanical properties. It contains between 20-30\% acrylonitrile. Increasing the amount of acrylonitrile increases the resistance of the copolymer to heat, impact and chemicals, but reduces its moulding property.

Polymethyl methacrylate have high light transmittance, long life, high resistance to ultraviolet rays and weather conditions, can be produced in the desired color and its surface is very hard. As well (it is) as $100 \%$ recyclable.

The shapes of valves made from the materials used in the study are given in Fig. 2 (b), (c), (d). It is known from both literature and experience that the mechanical properties of the valve made of brass (a) material are superior to the other three materials. For this reason, the tests were not applied to the brass material, but the appearance information of the valve was shared from the brass material mentioned in the study.

Some properties of the valves used in the experiment and produced in the plastic injection molding machine are given in Table 1.

Table 1. Some properties of materials used in the experiment [10]

\begin{tabular}{|c|c|c|c|c|c|}
\hline Property & unit & SAN & PA66 & PMMA & Method \\
\hline \multicolumn{6}{|l|}{ Physical } \\
\hline Density & $\mathrm{g} / \mathrm{cm}^{3}$ & 1.08 & 1.37 & 1.19 & ISO 1183 \\
\hline Water absorption (Equilibrium) & $\%$ & 0.20 & 1.9 & 0.30 & ISO 62 \\
\hline \multicolumn{6}{|l|}{ Hardness } \\
\hline Rockwell hardness (M-Scale) & $\mathrm{MPa}$ & 83 & 120 & 97 & ASTM D785 \\
\hline Ball indentation hardness (H 961/30) & $\mathrm{MPa}$ & 165 & 270 & 180 & ISO 2039-1 \\
\hline \multicolumn{6}{|l|}{ Mechanical } \\
\hline Tensile stress (Yield, $23^{\circ} \mathrm{C}$ ) & $\mathrm{MPa}$ & 75.0 & 200 & 70.0 & ISO $527-2$ \\
\hline Tensile strain (break, $23^{\circ} \mathrm{C}$ ) & $\%$ & 3.0 & 3.0 & 6.0 & ISO 527-2 \\
\hline Flexural stress & $\mathrm{MPa}$ & 125 & 280 & 103 & ISO 178 \\
\hline \multicolumn{6}{|l|}{ Impact } \\
\hline Charpy notched impact strength $\left(23^{\circ} \mathrm{C}\right)$ & $\mathrm{kJ} / \mathrm{m}^{2}$ & 2.0 & 12 & 2.0 & ISO 179 \\
\hline Charpy unnotched impact strength & $\mathrm{kJ} / \mathrm{m}^{2}$ & 18 & 80 & 11 & ISO 179 \\
\hline \multicolumn{6}{|l|}{ Thermal } \\
\hline $0.45 \mathrm{MPa}$, Unannealed & ${ }^{\circ} \mathrm{C}$ & 100 & 261 & 103 & ISO 75-2/B \\
\hline 1.8 MPa, Soft annealing & ${ }^{\circ} \mathrm{C}$ & 88.0 & 253 & 100 & ISO 75-2/A \\
\hline \multicolumn{6}{|l|}{ CLTE } \\
\hline Flow & $\mathrm{cm} / \mathrm{cm} /{ }^{\circ} \mathrm{C}$ & $7.0 \mathrm{E}-5$ & $2.2 \mathrm{E}-5$ & $6.5 \mathrm{E}-5$ & ISO $11359-2$ \\
\hline
\end{tabular}


Strain gauge was glued to the surfaces of the valves to accurately measure the expansion amounts of the three valves. In order to determine the expansion amounts in two directions, the strain gauge was applied at an angle of $45^{\circ}$ with the surface of the valve (Fig. 3 a).

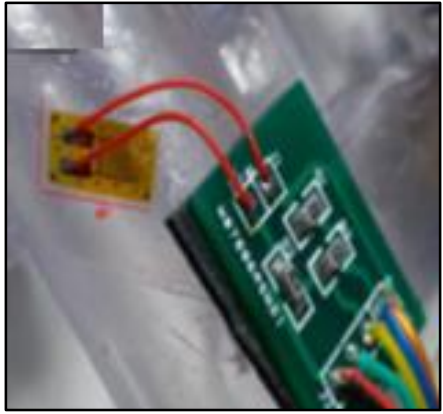

a)

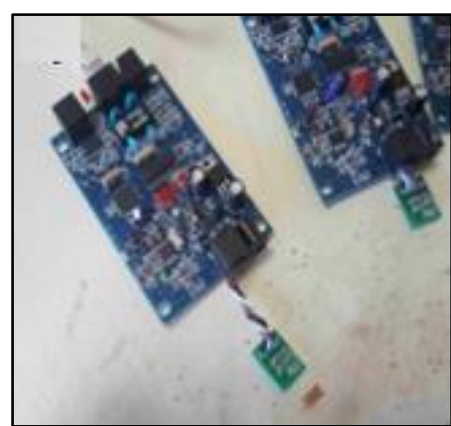

b)

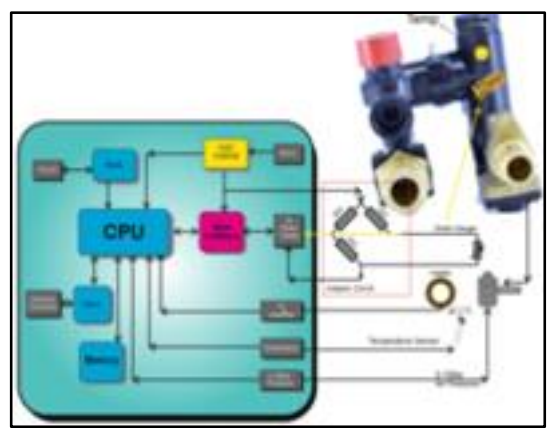

c)

Fig. 3. a) $45^{0}$ angle glued strain gauge on material; b) strain gauge circuits; c) structure of strain gauge measurement unit

According to this study, the data from three materials with the help of strain gauge circuits (Fig. 3 b) and strain gauge (Fig. $3 \mathrm{c}$ ) presented in the figure above, aiming automatically recording of the data obtained at the same conditions with different air pressures.

Strain is the amount of deformation an object experiences compared to its initial size and shape. Strain is a dimensionless quantity and is often expressed as a percentage. Because the amount of deformation is very small, it is expressed as a micro-strain unit. A microstrain is a millionth unity part of a strain-forming deformation. $\mu \varepsilon$ is used as the acronym for microstrain [11].

In the experimental assembly (Fig. 4 a), air heated to 31 and $51{ }^{\circ} \mathrm{C}$ passes through the three-way valve with the help of a compressor, and variable compressed air acts on all valves simultaneously, made of SAN (valve 1), PA66 (valve 2) and PMMA (valve 3).

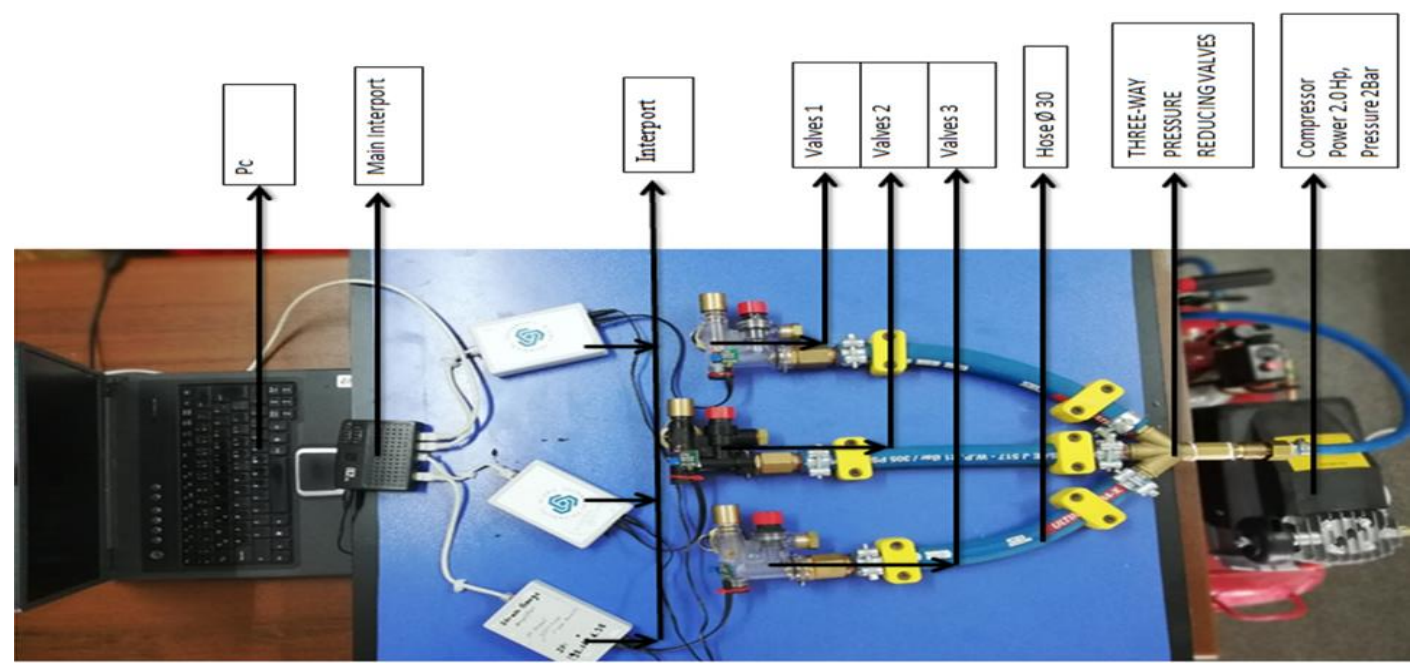

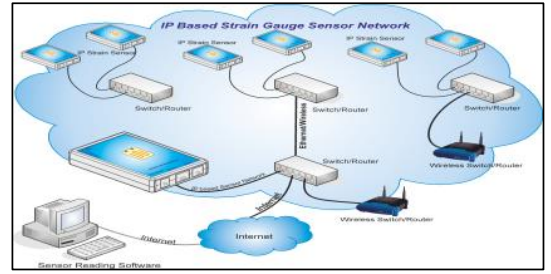

b)

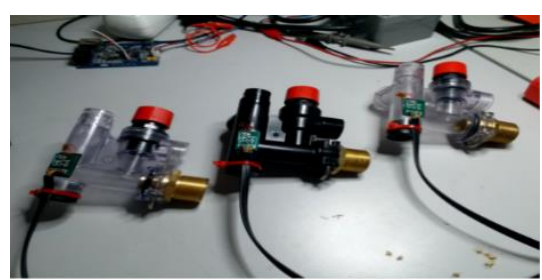

c)

Fig. 4. a) Experimental assembly; b) IoT-SGS software; c) IoT-SGS valves in this study 
RECENT, Vol. 22, no. 2(64), 2021

The degree of hot air applied to the inner surfaces of the valves was measured from the inside of the pipes with the help of a heat meter. Experimental temperature values (31 and 51) were recommended by Pakkens company. The experiment, which started at 0.5 bar, increased by 0.5 bar each time to 2.5 bar and was applied to valves. The applied compressed air is continuously controlled by both the pressure meter in the compressor and the electronic pressure meter in the strain gauge software. Expansion amounts obtained with strain gauge were transferred to main ports using inter ports and then to computer and data was recorded at degree intervals of seconds. Software that allows the transfer of expansion amounts (Fig. 4 b) and strain gauges (Fig. 4 c) attached to the same points of the valve surfaces are given.

\section{Results}

As a result of applying compressed air applied variably at $0.5,1.0,1.5,2.0$ and 2.5 bar to valves at temperatures of 31 and $51^{\circ} \mathrm{C}$, expansion amounts were determined in the experimental assembly.

If the applied air pressure is variable and the air temperature is constant at $31{ }^{\circ} \mathrm{C}$, the amount of expansion depending on the time.

When 0.5 bar pressure was applied at $31^{\circ} \mathrm{C}$, it was determined that the first expansion amount of valve $2(3383 \mu \varepsilon)$ with the first pressure was lower than other valves, however, valve $1(3759 \mu \varepsilon)$ and valve $3(3660 \mu \varepsilon)$ had expansion amounts (Fig. 5). Although the amount of expansion increases as the duration of the applied pressure increases in seconds, no serious change has been detected due to the small amount of applied pressure.

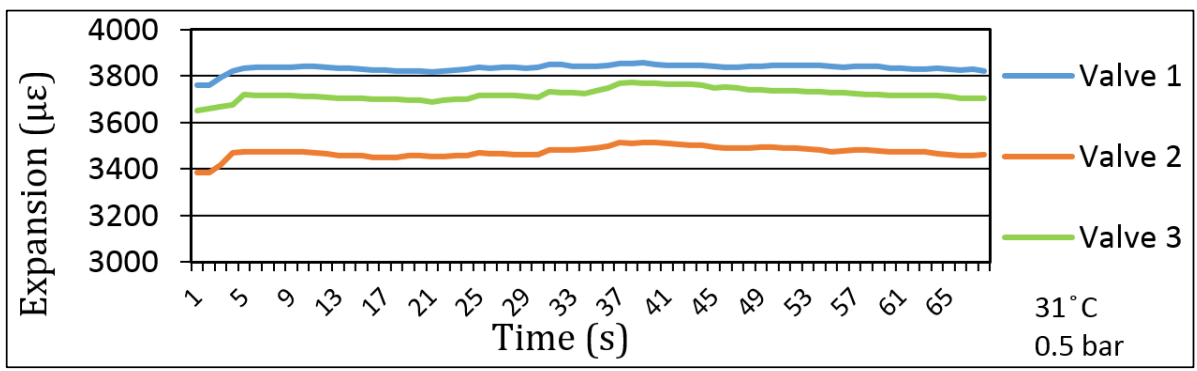

Fig. 5. Expansion amounts of valves at $31^{\circ} \mathrm{C}$ and 0.5 bar

When 1.0 bar pressure was applied at $31^{\circ} \mathrm{C}$, the amount of expansion due to the first compressed air of valve 1 and valve 3 was determined to be high valence (Fig. 6). When the application of compressed air continued, no serious change in the amount of expansion was observed.

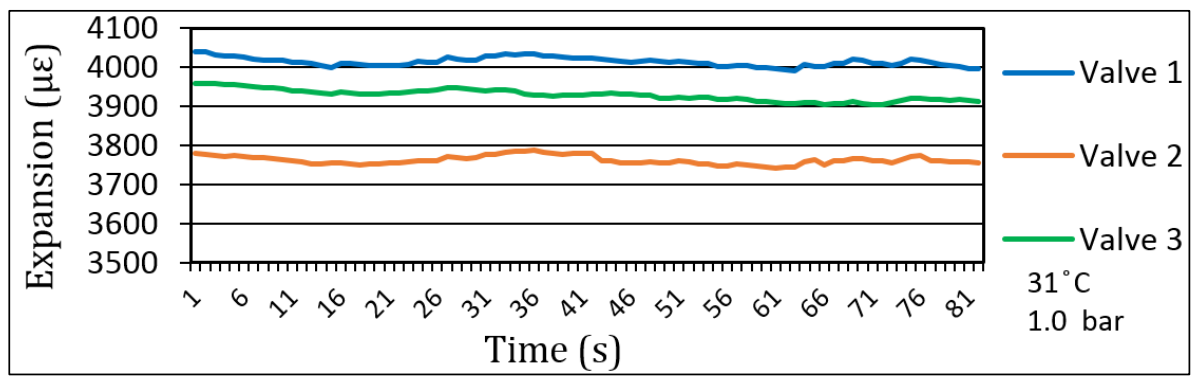

Fig. 6. Expansion amounts of valves at $31^{\circ} \mathrm{C}$ and 1.0 bar

At Figure 7, although the expansion amounts of the valves increase at the same rate under a pressure of 1.5 bar at $31^{\circ} \mathrm{C}$, the valve 3 has been observed to expand less than other valves. Valve 1 has been identified as the valve with the most expansion amount.

At $31^{\circ} \mathrm{C}$ and 2.0 bar pressure, Fig. 8 shows that the expansion amounts in the valves increase, but the increase in the expansion amount in valve 3 was found to be greater than in other valves.

Under a pressure of 2.5 bar at $31^{\circ} \mathrm{C}$, the increase in the amount of valve 1 expansion is considerable (Fig. 9). In addition, with high pressure, the expansion amount of valve 2 increased more than valve 3. 
RECENT, Vol. 22, no. 2(64), 2021

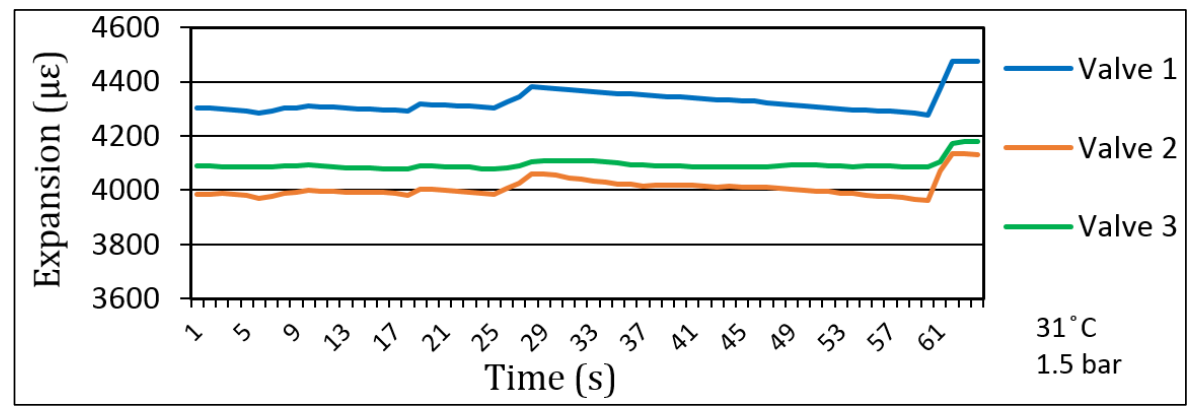

Fig. 7. Expansion amounts of valves at $31^{\circ} \mathrm{C}$ and $1.5 \mathrm{bar}$

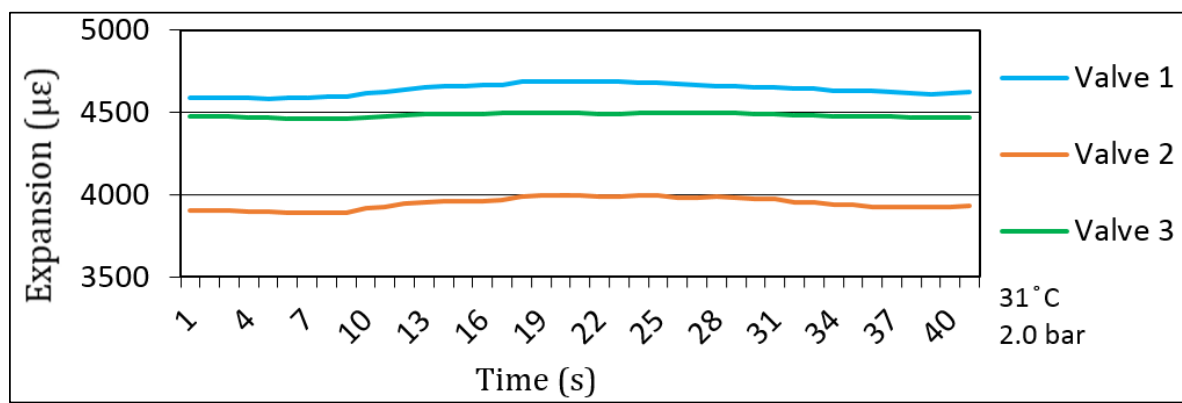

Fig. 8. Expansion amounts of valves at $31^{\circ} \mathrm{C}$ and 2.0 bar

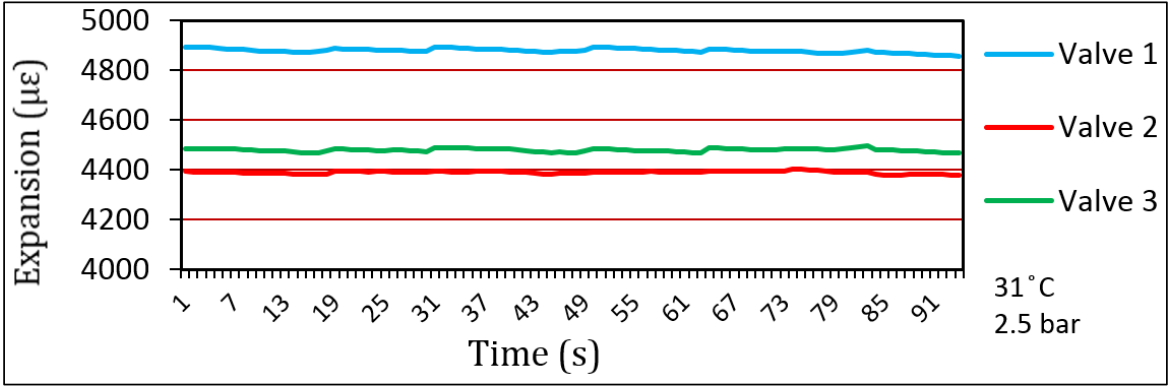

Fig. 9. Expansion amounts of valves at $31^{\circ} \mathrm{C}$ and 2.5 bar

If the applied air pressure is variable and the air temperature is constant at $51{ }^{\circ} \mathrm{C}$, the amount of expansion also depends on the time.

Figure 10 clearly shows, how at $51{ }^{\circ} \mathrm{C}$ below 0.5 bar, the expansion amount of valve 1 is the most increased compared to other valves. Valve2 and valve3 have the lowest expansion valence of valve 2, although they have a valence close to each other in the expansion rates.

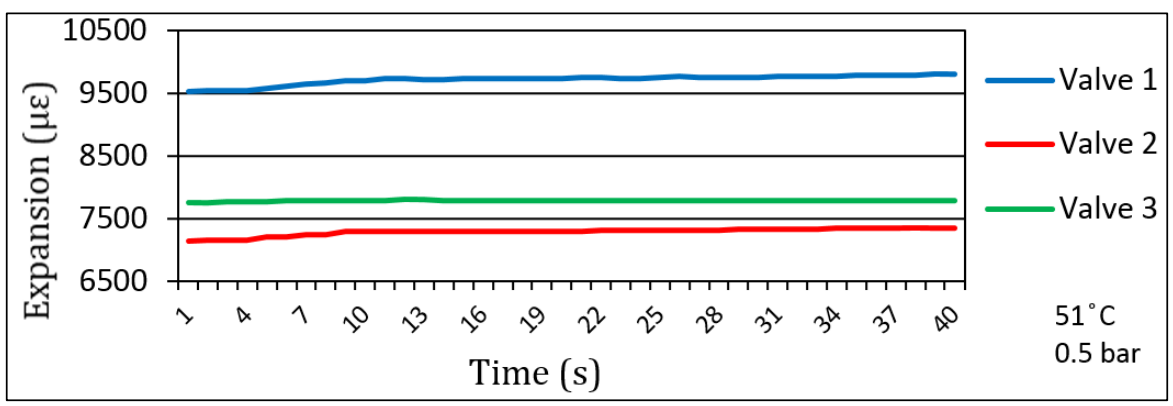

Fig. 10. Expansion amounts of valves at $51^{\circ} \mathrm{C}$ and 0.5 bar

Figure 11 represents the behaviour of the three valves with pressure of 1.0 bar and temperature of $51{ }^{\circ} \mathrm{C}$. Valve 1 expansion value is the highest, while the other two valve's values (valve 2 and valve 3) are very similar. 
RECENT, Vol. 22, no. 2(64), 2021

Figure 12 gives a picture of increasing the pressure to 1.5 bar and temperature at $51^{\circ} \mathrm{C}$, the expansion amounts in all valves increase at the same rate, but in time stay constantly.

Figure 13 shows that, when 2.0 bar is applied at $51^{\circ} \mathrm{C}$, valve 1 has the highest amount of expansion, and valve 2 and valve 3 have been shown to increase expansion rates along with increased compressed air.

When 2.5 bar was applied at $51^{\circ} \mathrm{C}$, valve 1 showed a significant expansion compared to other valves, Fig. 14, but valve 2 and valve 3 had close values. Valve 2 had the lowest expansion rate compared to other valves.

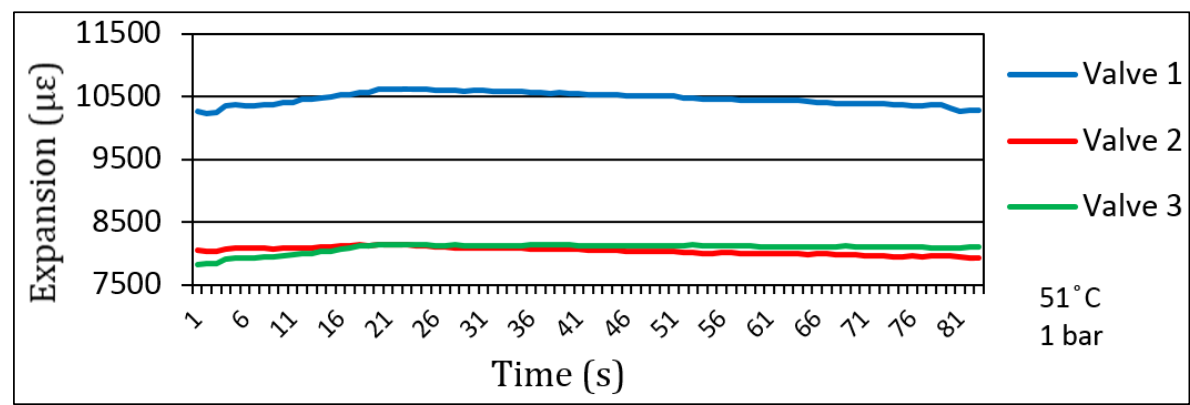

Fig. 11. Expansion amounts of valves at $51{ }^{\circ} \mathrm{C}$ and 1 bar

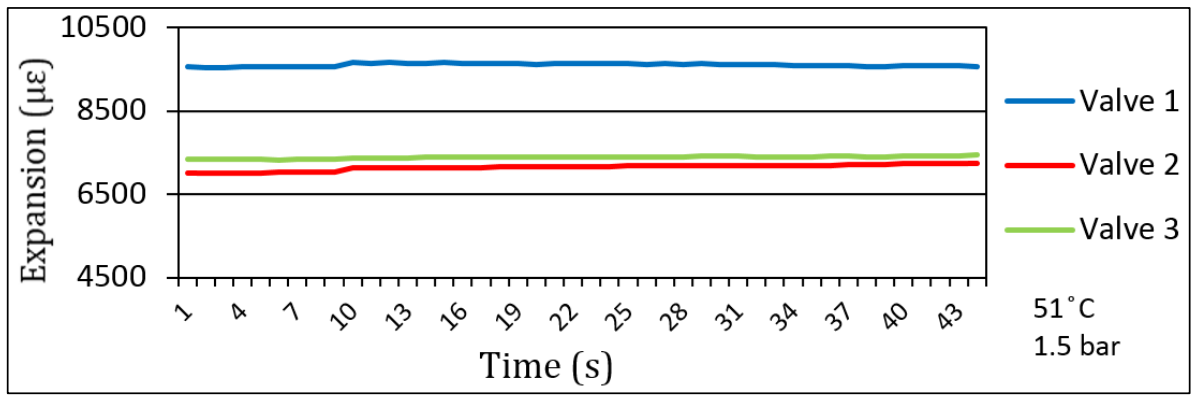

Fig. 12. Expansion amounts of valves at $51^{\circ} \mathrm{C}$ and 1.5 bar

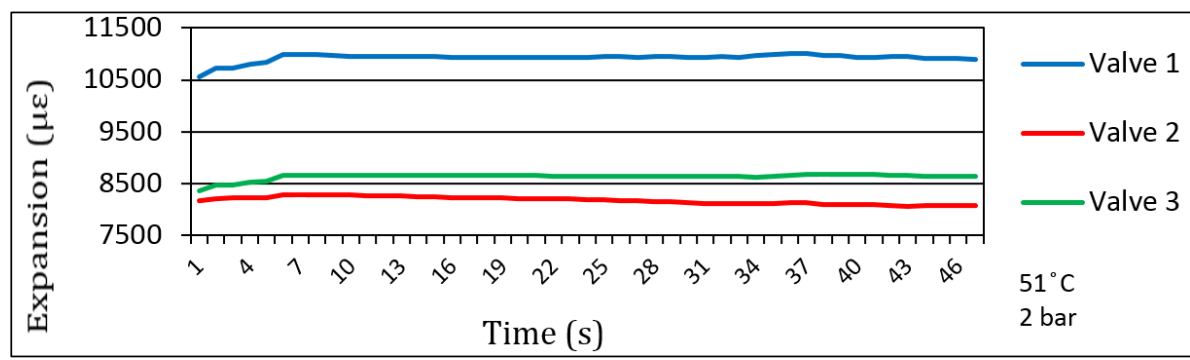

Fig. 13. Expansion amounts of valves at $51^{\circ} \mathrm{C}$ and 2 bar

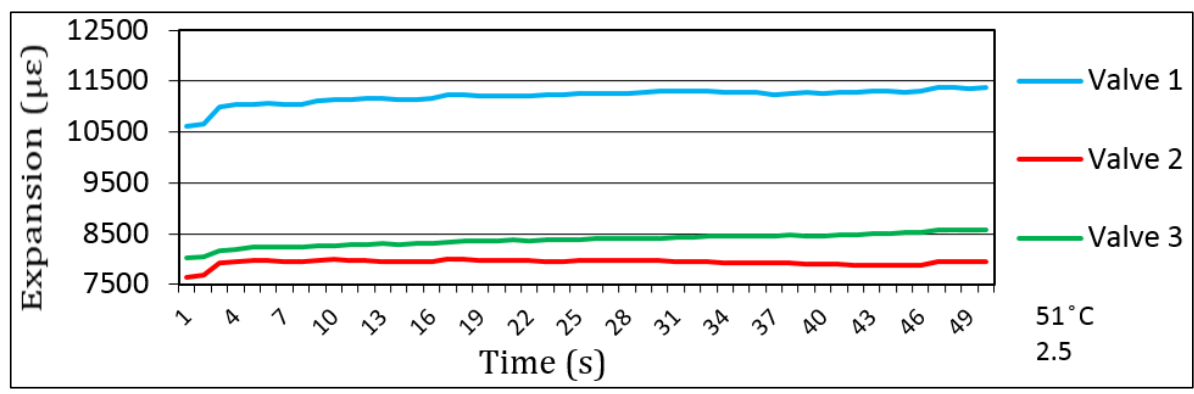

Fig. 14. Expansion amounts of valves at $51^{\circ} \mathrm{C}$ and 2.5 bar

As a result of the experiments, figures 5-14 is given above in the form of a graph with the amount of expansion obtained with the help of strain gauge glued to the surfaces of the valves degree. Below is the 
amount of expansion that occurs when the air pressure applied to the valves at 31 and $51{ }^{\circ} \mathrm{C}$ is increased from 0.5 bar to 2.5 bar.

Valve $3(3760 \mu \varepsilon)$ has been found to have the highest amount of expansion, while valve $2(3418 \mu \varepsilon)$ has the lowest amount of expansion when the compressed air is between 0.5 bar and 2.5 bar and is applied at $31{ }^{\circ} \mathrm{C}$, see Figure 15. The amount of pressure was increased up to 2.5 bar and it was determined that valve $1(4867 \mu \varepsilon)$, valve $2(4473 \mu \varepsilon)$ and valve $3(4764 \mu \varepsilon)$ had expansion values.

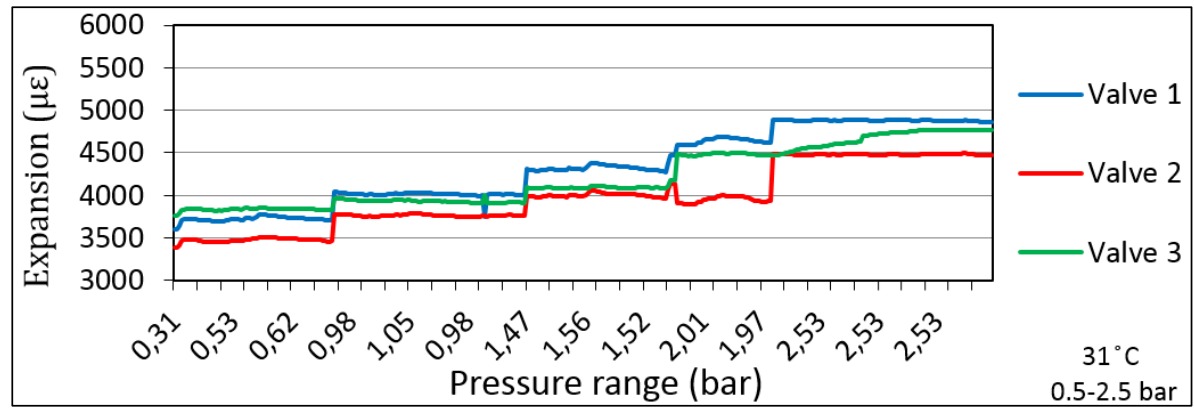

Fig. 15. Expansion amount of valves from 0.5 to 2.5 bar at $31^{\circ} \mathrm{C}$

Valve 2 had the lowest $(7153 \mu \varepsilon)$ initial expansion when compressed air ranging from 0.5 bar to 2.5 bar at $51{ }^{\circ} \mathrm{C}$, while valve $3(7772 \mu \varepsilon)$ expanded less pressure than valve $2(9544 \mu \varepsilon)$, see Figure 16 . But with increased temperature and pressure, valve 1 has had a greater amount of expansion compared to other valves.

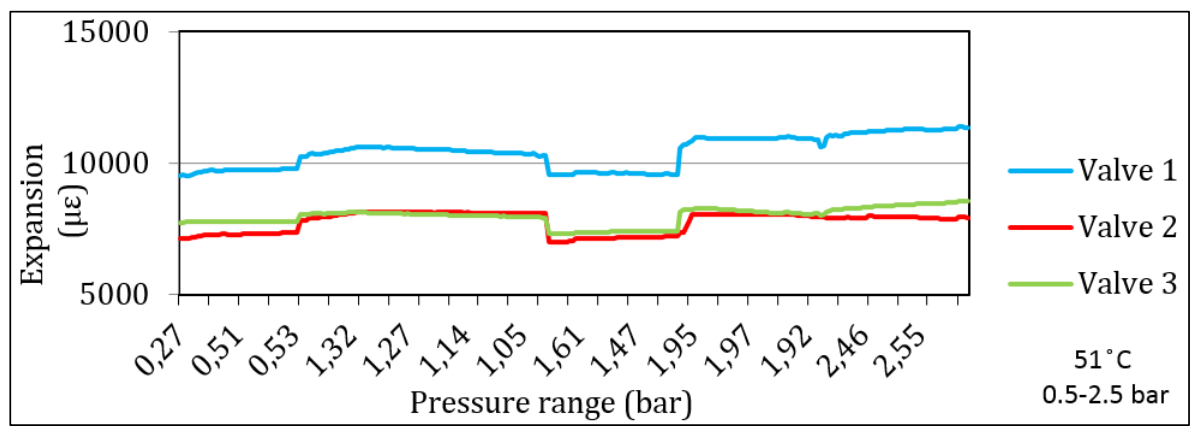

Fig. 16. Expansion amount of valves from 0.5 to 2.5 bar at $51^{\circ} \mathrm{C}$

\section{Conclusion}

Because of its many advantages over traditional materials, the use of composite materials is increasing every day. In this paper, has been studied if the materials identified are suitable for an alternative to brass material. The research findings resulted in recommendation to the company for the usage of three alternative materials. It was provided that the valves used in the experiment did not require a second process due to the production methods, and the production time took less time compared to the brass material produced by the casting method. For this reason, it has become a necessity for the company to choose a new material.

No significant amount of expansion has been detected materials at $31^{\circ} \mathrm{C}$. But when the temperature rises to $51^{\circ} \mathrm{C}$, it was found that the valve consisting of SAN (valve 1) material has a much greater amount of expansion than other valves.

Valves made from PA66 (valve 2) and PMMA (valve 3) materials were determined to have similar values by means of experiments conducted under the specified conditions. The fact that the applied pressure was not selected too high considering the actual operating conditions was the reason why we could not decipher large differences between the amount of expansion of materials PA66 (valve 2) and PMMA (valve 3) close to one.

Given all the operating conditions of the valve being tested and looking at the data obtained as a result of the experiment, it was recommended that PA66 material can be used by the company instead of the valve produced from brass. 


\section{References}

1. Bayraktar Ö. (2016): System Design, Manufacturing and Composite Material Production for Prestressed Carbon Fiber Reinforced Composites Production. M.Sc. Thesis, University of Gazi, Ankara, https://docplayer.biz.tr/61025645-Ongerilimli-karbon-elyaf-takviyeli-kompozit-uretimi-icin-sistemtasarimi-imalati-ve-kompozit-malzeme-uretimi-omer-bayraktar.html

2. Erkal, Ö.G. (2015): Effects of different curing cycles on glass transition temperature of carbon epoxy composites. M.Sc. Thesis, University of Gazi, Ankara, https://docplayer.biz.tr/59938195-Karbon-epoksi-kompozitincamsi-gecis-sicakligi-uzerine-farkli-kurlesme-cevrimlerinin-etkisi-ozlem-guney-erkal.html

3. Ersoy H. (2001): Composite Material. Literary Publishing, ISBN 978-9758431472

4. Chawla K.K. (2011): Composite Materials. Springer, 3 $3^{\text {rd }}$ edition, ISBN 978-0-387-74364-6, eISBN 978-0-38774365-3, DOI 10.1007/978-0-387-74365-3

5. Boley B.A., Weiner J.H. (1997): Theory of Thermal Stress. Dover Publications, ISBN 978-0-486-14386-6 (eBook)

6. Ketan R. (2009): Strain Gauge. Santa Clara University, https://inderjitsingh87.weebly.com/uploads/2/1/1/4/ 21144104/rasal - strain gauge combined.pdf

7. https://www.pakkens.com/tr/products?valves

8. de Souza A.C., Pires A.T.N., Soldi V. (2002): Thermal stability of ferrocene derivatives and ferrocene-containing polyamides. Journal of Thermal Analysis and Calorimetry, ISSN 1588-2926, 1388-6150, Vol. 70, article 405, https://doi.org/10.1023/A:1021664221582

9. Bahr U., Lüderwald I., Müller R., Schulten H.-R. (1984): Pyrolysis field desorption mass spectrometry of polymers. III. Aliphatic polyamides. Die Angewandte Makromolekulare Chemie, ISSN 0003-3146, Vol. 120, is. 1, pp. 163-175, https://doi.org/10.1002/apmc.1984.051200110

10. https://www.dupont.com/products/zytel.html. (access date: 14.12.2021)

11. https://www.me-systeme.de/en/support/units-conversion/strain. (access date: 14.12.2021) 